\title{
INVESTIGATION OF THE EFFICIENCY OF USE OF POLYCOMPONENT ACIDIFIERS IN THE TECHNOLOGY OF RYE-WHEAT BREAD
}

\author{
Tatyana Sylchuk \\ Department of hotel-restaurant business \\ National University of food technologies \\ 68 Volodymyrska str., Kyiv, Ukraine, 01601 \\ tsnuft@gmail.com \\ Olena Bilyk \\ Department of Technology of bakery and confectionery products \\ National University of food technologies \\ 68 Volodymyrska str., Kyiv, Ukraine, 01601 \\ bilyklena@gmail.com \\ Volodymyr Kovbasa \\ Department of Technology of bakery and confectionery products \\ National University of food technologies \\ 68 Volodymyrska str., Kyiv, Ukraine, 01601 \\ kovbasavm19091@ukr.net \\ Vira Zuiko \\ Department of hotel-restaurant business \\ National University of food technologies \\ 68 Volodymyrska str., Kyiv, Ukraine, 01601 \\ virazuiko@gmail.com
}

\begin{abstract}
The polycomponent acidifiers "Optimal 1" and "Optimal 2" were elaborated at the National University of food technologies (Kyiv city, Ukraine) for intensifying the technology of rye-wheat bread and prolongation of its freshness.

The composition of acidifiers includes the enzymatic preparations (EP) Glusim 10000 Mono (glucose oxidase) that favors the improvement of structural-mechanical properties of dough, EP Pentopan 500 BG (mixture of pentosanase and hemilcellulase) that favors the modification of non-starched polysaccharides and provides elastic crumb.

For providing the proper dough acidity and intensification of the process of dough fermentation, the acidifier composition is added with citeric acid and dry milk serum (DMS), and for improving organoleptic parameters - with rye fermented malt (RFM).

For increasing dough water-absorbing ability and keeping products' freshness in the process of storage, guar gum is added.

The optimal dosage of PCA "Optimal 1" and "Optimal 2" in the recipe of rye-wheat bread is $2 \%$ to the flour mass.

There are considered technological aspects of acidifiers use. There are considered processes, connected with stalling, loss of organoleptic and physical-chemical parameters of the bread quality at storage. The positive effect of acidifiers on the parameters of crumbling and swelling of bread crumb at the accelerated technology of its preparation. It was established, that the use of acidifiers favors the deceleration of rye-wheat bread staling. There was obtained the positive influence of acidifiers on preserving smell and taste of ready products. The obtained results prove the expedience of using the elaborated polycomponent acidifiers "Optimal 1" and "Optimal 2" in the technology of rye-wheat bread at its accelerated preparation. The use of the elaborated acidifiers favors the shortening of the technological process of rye-wheat bread production in 2,5-3 times and provide freshness, taste and smell preservation in ready products.

Keywords: acidifier, rye-wheat bread, staling, starch retrogradation, food additives, crumbling, organic acids, free and bound moisture.
\end{abstract}

\section{Introduction}

Marketing studies, carried out among average consumers of bakery products of Ukraine, indicate that the essential part of the population prefer rye-wheat sorts of bread [1]. 
The traditional technology of rye-wheat sorts of bread is a complicated and long technological process that is conditioned by features of carbohydrate-amylase and protein-proteinase complexes of rye flour. It is also conditioned by features of the rye flour dough structure and characteristics of the main raw material - rye flour, which bakery features differ from wheat one. For providing the normal course of the process of dough-creation it is necessary to provide the decrease of $\alpha$-amylase activity, rather deep swelling and peptization of proteins and peptosans. It needs to attain the essential dough acidity at dough-creation that is possible at using dense and liquid rye leavens with the high acidity [2].

The modern accelerated technologies provide the use of acidifiers and improvers, directed on providing the high dough activity. The use of these improvers allows to simplify the technology of rye-wheat bread [3].

The polycomponent acidifiers "Optimal 1" [4] and "Optimal 2" [5], based on organic acids, enzymatic preparations and food additives were elaborated at the National University of food technologies (Kyiv city, Ukraine).

This work is directed on establishing the optimal dosage of the elaborated polycomponent acidifiers for the rye-wheat bread production and on studying their influence of the technological process and products quality.

\section{Materials and Methods}

The polycomponent acidifiers, elaborated at the National University of food technologies (Ukraine) consists of:

"Optimal 1" - enzymatic preparations Glusim 10000 Mono and Pentopan 500 BG ("Novozymes" (Denmark)), guar gum, citric acid, dry milk serum, rye fermented malt;

"Optimal 2" - enzymatic preparation Fungamil Super ("Novozymes" (Denmark)), ascorbic acid, guar gum, citric acid, dry milk serum, rye fermented malt.

The complex bakery improver "Ibis" (France, "Lesaffre" company) contains citric acid, barley malt and wheat flour. The recommended dosage $0,5 \ldots 1,5 \%$ to the flour mass.

Rye-wheat bread was prepared by the recipe:

- wheat peeled flour ("Kyivbread" (Ukraine)) - 50,0 kg;

- wheat flour of the first sort ("Kyivbread" (Ukraine)) - 50,0 kg;

- bakery pressed yeast ("Ensim” (Ukraine) - 0,5 kg;

- kitchen food salt (PSC “GALKA-DROGOBYCH (Ukraine)) - 1,5 kg;

- white crystal sugar ("BORSCHIVSKY SUGAR PLANT" company) (Ukraine)) - 3,0 kg.

The laboratory baking was realized for studying parameters of the physical process, biochemical, physical-chemical changes in dough and quality parameters of bread. Dough was prepared by the traditional technologies on dense leavens [6] and by the accelerated technology at using the complex bakery improver (1,0\% to the flour mass) and elaborated polycomponent improvers "Optimal 1" and "Optimal 2" (2,0\% to the flour mass). Acidifiers were mixed with sifted flour. Yeast, sugar and salt were dissolved in water with the temperature $32 \ldots 35{ }^{\circ} \mathrm{C}$. Dough was mixed with the mass share of moisture $47 \%$ in the dough-mixing machine with the gradual increase of turns during 5 minutes. The dough fermentation and semi-products maturing after the processing were realized in the maturing chamber with the raised humidity at the temperature $35 \ldots 37^{\circ} \mathrm{C}$. Semi-products were baked in the stove at the temperature $200 . .220^{\circ} \mathrm{C}$ at the relative humidity of the medium $50 . .60 \%$ up to the readiness.

The optimal dosage of acidifiers was determined by the method of the experimental-statistical modeling. At that the plan of the experiment with mutually dependent variables - specific volume of ready products and concentration of separate additives was used. The search for parameters of the extremum of the function of the multifactor experiment was realized by the method of Box-Wilson in the program of the "rapid ascent" [7]. As a result we received the regression equation, on which base the graphic presentation was built using the system of the statistic analysis of data Statistica 6.0 (version 2010). This method allows to determine the optimal dosage of variation factors for obtaining the model of the maximal productivity. 
The studied samples of ready products were kept at the temperature $(20 \pm 2)^{\circ} \mathrm{C}$ and relative humidity $(75 \pm 2) \%$. The assessment of the quality was realized in 4, 24, 48 and 72 hours of storage after the baking.

The bread quality was assessed by physical-chemical (specific volume, form-stability, structural-mechanical properties of crumb) and organoleptic parameters (appearance, crust surface state, porosity structure, smell, taste). The duration of freshness keeping by products was studied by the change of structural-mechanical properties of crumb. Its general deformation after 72 hours of storage was determined on the penetrometer AP 4/1 ("Finemass" (Germany)) [8].

The degree of products staling was studied also by the crumb swelling in ready products and their crumbling. The staler bread, the less swelled crumb is. The staling degree is expressed by the value of the specific swelling of the swelled mass in $\mathrm{cm}^{3}$ for $1 \mathrm{~g}$ of the dry substance of the studied sample [9]. The crumbling was assessed by crumbles creation as a result of the rubbing of two pieces of bread crumb with the mass $5 \mathrm{~g}$, cut in the parallelepiped form as a result of shaking off during 5 min in the vibration shaker IKA HS 501 digital (IKA ${ }^{\circledR}$-Werke GmbH \& Co. KG (Germany)). The crumbling was expressed at the ratio of the crumb mass to the bread batch mass in percents.

The change of forms of moisture binding in bakery products crumb during their storage was assessed by the thermographic method of the study of bound moisture on the derivatograph Q-1500 (MOM firm of Paulik-Paulik-Erdey system (Hungry) in the temperature diapason $20-200{ }^{\circ} \mathrm{C}$. The essence of this method is in fact that the sample and etalon are loaded in the working chamber and heated with the permanent speed. At that the sample temperature is measured, and the difference between sample's and etalon's temperatures is continuously registered using the differential thermocouple. In parallel with measurements of the temperature of the working and etalon samples, their mass is controlled. At heating the moisture removing takes place that leads to the decrease of the sample mass [9].

The content of aromatic substances in products was assessed by the quantity of bisulphite-binding compounds [10]. This method is based on the ability of aldehydes and some ketones binding by sodium bisulphites, creating adducts. This method is in the preliminary removing of non-reacted bisulphite with the further destruction of adducts by sodium bicarbonate and titration of released bisulphite, equivalent to the content of carbonyl compounds.

The processing of experimental researches results were realized using the methods of the calculation of the statistical reliability of measurement results. Approximations of empirical data were realized using e-tables MSExcel (version of 2010).

\section{Results}

According to the traditional technology, the dough semi-product is added with leavens that contain strains of lactate bacteria, have the essential humidity and acidity 10-14 degrees. As far as the use of a leaven complicates and prolongs the technological process, there was realized the search for alternative substances that would raise the medium acidity.

It is known, that a leaven together with yeast in a correspondent temperature of the medium favors the alcoholic and lactate fermentation, in which result ethanol, carbon dioxin, milk acid volatile acids are created. It is well-known, that the content of di- and three-carbonic acids in dough has the important value. Citric acid is the one of used in the technology of bakery products.

Milk acid is accumulated in the process of rye-wheat dough fermentation. The shortening of the technological process duration needs the introduction of dry milk serum that compensates the lack of milk acid and also contains nitrogen substances and amino acids that have the direct influence on structural-mechanical properties of a semi-product and ready product [11].

Except the introduction of organic acids, enzymatic preparations of different directions were added to the content of the elaborated acidifiers. Among enzymatic preparations, offered for the bakery production, enzymatic preparation of Novozymes (Denmark) were separated. Among enzyme groups, offered for improving rye and rye-wheat products we separated Fungamyl Super AX, Pentopan 500 BG and Glusim 10000 Mono. Glusim 10000 Mono (glucose oxidase) causes the oxidation of free sulfhydryl groups of protein and creation of disulphide links that favors cellulose strengthening and, as a result, improves dough structural-technological properties. Pentopan 
$500 \mathrm{BG}$ (pentosanase) favors the dissociation and modification of the fraction of non-starch polysaccharides in flour that has a positive influence of the structure of rye-wheat dough.

It is well-known, that the introduction of Fungamyl Super AX enzyme in the symbiosis with ascorbic acid favors the increase of sugars accumulation that conditions the improvement of gas-creation by $15 \ldots .20 \%$. Ascorbic acid also gives the additional oxidative effect at the expanse of its transformation in dehydro- $L$-ascorbic acid under the effect of hydroperoxides that are oxidizers in dough systems.

For improving the general number of reducing sugars and catalyzation of taste and smell substances creation, the content of the elaborated mixture was added with fermented malt. This component provides the strengthening of the gluten frame and decrease of the free moisture quantity. The addition was introduced in the quantity $0,5 \ldots 1,0 \%$ to the flour mass.

The introduction of guar gum provides the increase of the water-absorbing ability and decreases the degree of dough tenuity, and also favors the formation of the even porosity and strengthening of epy weak cellulose that provides the increase of ready products specific volume. The addition of gum causes the increase of somatically bound humidity, caused by the increase of storage terms of a product at the expanse of decreasing parameters of its staling. According to the studies, it was determined, that the optimal effect from the gum introduction is obtained at its dosage $0,2 \ldots 0,5 \%$ to the main raw material mass [12].

Based on selected components, taking into account producers' recommendations, review of literary sources and test baking, there was determined the content of additives in epy polycomponent mixture of acidifiers using methods of the experimental-statistic modeling.

For the "Optimal 1" the essential influence of the bread quality is inherent to such optimization factors as the enzymatic preparation Glusim 10000 Mono (glucose oxidase), Pentopan 500 BG (pentosanase and hemylcelulase) and guar gum. The specific volume of rye-wheat bread was selected as a criterion of optimality. The search for parameters of the extremum of the function of the multifactor experiment was realized by the method of Box-Wilson in the program of the "rapid ascent". Intervals of experimental factors variation are presented in Table $\mathbf{1 .}$

Table 1

Diapasons of the factor space for the polycomponent acidifier "Optimal 1"

\begin{tabular}{cccc}
\hline Name & \multicolumn{2}{c}{ Studied factors, \% to the flour mass } \\
& $\mathbf{X}_{\mathbf{1}}$, Glusim $\mathbf{1 0 0 0 0}$ Mono & $\mathbf{X}_{2}$, Pentopan 500 BG & $\mathbf{X}_{\mathbf{3}}$, guar gum \\
\hline Zero factor level & 0,006 & 0,003 & 0,25 \\
Variation interval & 0,002 & 0,002 & 0,1 \\
Higher level & 0,008 & 0,005 & 0,35 \\
Low level & 0,004 & 0,001 & 0,15
\end{tabular}

The specific volume of rye-wheat bread was chosen as an optimization parameter.

The optimal number of experimental factors of the acidifier "Optimal 1", namely EP Glusim 10000 Mono, Pentopan 500 BG and guar gum was established according to the program of rapid ascent. The graphic presentation of this expression, obtained using Statistica 6.0 system for the statistical analysis of data is presented on Fig. 1.

The analysis of the received graph allows to state, that the yellow diapason of the build area that corresponds to the optimal value of the specific volume of rye-wheat bread is equal to values of zero experiment factors.

The quantity of the other components of acidifiers, especially rye fermented malt, dry milk serum and citric acid was determined by the method of laboratory baking, analyzing their influence on the duration of the technological process, specific volume, porosity, acidity, crumb state and main organoleptic parameters of ready products. Citric acid and rye fermented malt were added in the quantity of $0,6 \ldots 0,9 \%$ to the flour mass DMS was added in the quantity of $0,15 \ldots 0,35 \%$. 


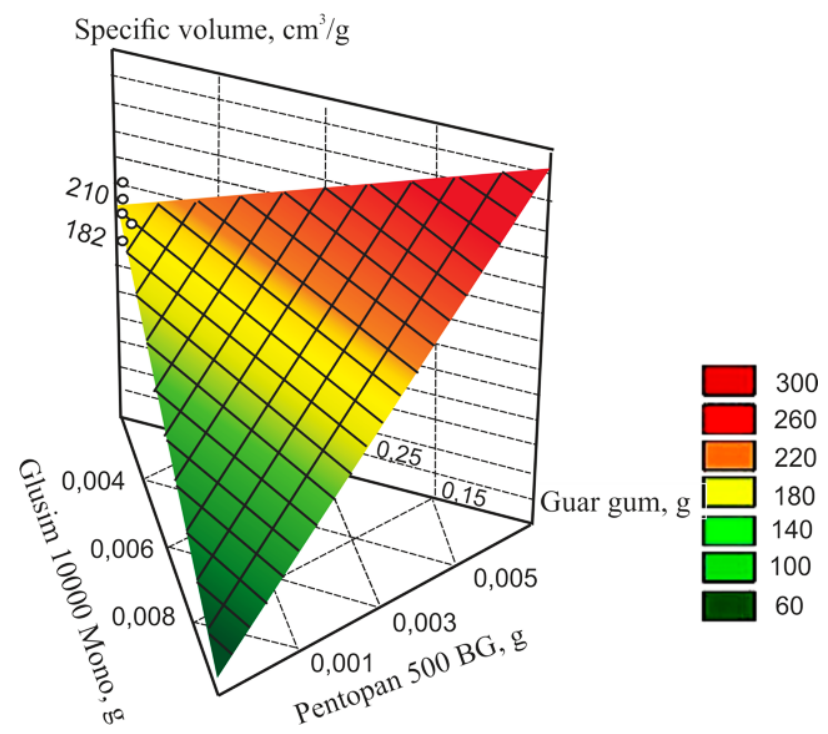

Fig. 1. The dependence of the specific volume change from the quantity of introduced Glusim 10000 Mono, Pentopan 500 BG and guar gum

The ratio between components of the polycomponent acidifier "Optimal 1" was determined on the base of the experimental-statistic analysis and test laboratory baking, $\mathrm{g} / 1000 \mathrm{~g}$ of flour:

- Glusim 10000 Mono - 0,006;

- Pentopan 500 BG - 0,003;

- guar gum - 0,25;

- citric acid - 0,75;

- dry milk serum - 0,25;

- rye fermented milk - 0,75.

The optimal dosage of the acidifier is $2,0 \%$ to the flour mass.

Optimization factors that influence the ready products quality of PCP "Optimal 2" are the enzymatic preparation Fugamyl Super AX (contains fungal $\alpha$-amilase and pentosanase), ascorbic acid and guar gum. Variation intervals of factors are presented in Table 2.

Table 2

Diapasons of the factor space for the polycomponent acidifier "Optimal 2"

\begin{tabular}{|c|c|c|c|}
\hline \multirow{2}{*}{ Name } & \multicolumn{3}{|c|}{ Studied factors, $\%$ to the flour mass } \\
\hline & Fungamyl Super AX & Ascorbic acid & $\mathbf{X}_{3}$, guar gum \\
\hline Zero factor level & 0,007 & 0,01 & 0,25 \\
\hline Variation interval & 0,002 & 0,005 & 0,1 \\
\hline Higher level & 0,009 & 0,015 & 0,35 \\
\hline Low level & 0,005 & 0,005 & 0,15 \\
\hline
\end{tabular}

The specific volume of rye-wheat bread was also chosen as an optimization parameter of the mathematical-statistic model "Optimal 2" The optimal ratio of Fungamyl Super AX, ascorbic acid and guar gum in the composition of the acidifier "Optimal 2" was established according to the program of rapid ascent and its graph presentation. The graphic presentation of this expression, obtained using Statistica 6.0 system for the statistical analysis of data is presented on Fig. 2.

The optimum values of the specific volume of rye-wheat bread that correspond to values of zero experimental factors are placed in the yellow diapason of the build area. 


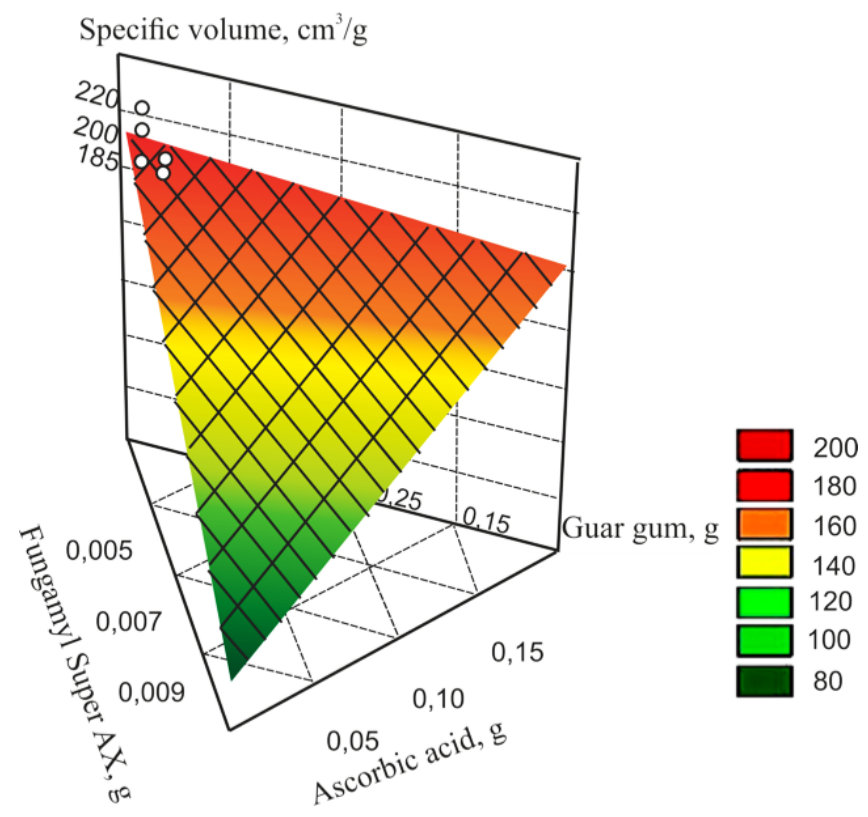

Fig. 2. The dependence of the specific volume change on the quantity of EP Fungamyl Super AX, ascorbic acid and guar gum

The final ratio between components of the polycomponent acidifier "Optimal 2" was determined on the base of the analysis of preliminary studies and experimental-statistic analysis $\mathrm{g} / 1000 \mathrm{~g}$ of flour:

- Fungamyl Super AX - 0,007;

- ascorbic acid - 0,01;

- guar gum - 0,25;

- citric acid - 0,75;

- dry milk serum - 0,25;

- rye fermented malt $-0,75$.

The optimal dosage of the acidifier is $2,0 \%$ to the flour mass.

The influence of introducing the elaborated acidifiers on the technological process of the rye-wheat bread production and also on quality parameters of semi-products and ready products was determined (Table 3).

It was determined, that time losses for the fermentation of semi-products with PCA are 3 times less comparing with products on the traditional leaven, for the maturing in 1,5 times. In samples with introducing "Ibic" improver the maturing in by $20 \%$ longer comparing with samples that PCA "Optimal 1" and "Optimal 2" were introduced. Despite the short time of the fermentation and maturing, the final acidity value for studied test semi-products with acidifiers is by $4-8 \%$ higher comparing with the control. It is known, that the great importance is inherent to parameters of the specific volume of rye and rye-wheat products. According to the data of Table 3, it is obvious, that the improvers' introduction favors the increase of this parameter in 3 times.

At using the elaborated additives to widen the assortment of rye-wheat bread, it was established, that PCA "Optimal 1" provides the better quality of rye-wheat bread at the ratio of rye and wheat flour in dough 80:20, 70:30, 60:40, and PCI "Optimal 2" is more effective at the more content of wheat flour in dough, namely at the ratio of rye and wheat flour in dough 20:80, 30:70, 40:60.

The guar gum introduction in PCA content favors the keeping of moisture at bread storage at the expanse of the high water-absorbing ability of the additive that favors the keeping of bread freshness better than at existent accelerated technologies. It was established, that losses of bound moisture in bread samples with elaborated PCA are less than in ones at the existent accelerated technology with "Ibis" improver. 
At storage the content of carbonyl compounds in both control samples and ones with polycomponent acidifiers samples decreases, especially in crust at the expanse of vanishing bisulphite-binding compounds into the external medium, and also partial diffusing in crumb. At introducing polycomponent acidifiers the loss of bisulphite-binding compounds at storage is less comparing with the traditional technology at the expanse of components of the elaborated polycomponent acidifiers.

Table 3

The influence of the polycomponent acidifiers on the technological process and products quality $n=3, p \leq 0,95$

\begin{tabular}{|c|c|c|c|c|}
\hline & \multicolumn{2}{|c|}{ Control } & \multicolumn{2}{|c|}{ With PCP } \\
\hline & With leaven & With improver "Ibis" & “Optimal 1" & "Optimal 2" \\
\hline \multicolumn{5}{|c|}{ Dough } \\
\hline Fermentation duration, min & 90 & 30 & 30 & 30 \\
\hline Maturing duration, min & 60 & 45 & 35 & 35 \\
\hline \multicolumn{5}{|l|}{ Acidity, degrees } \\
\hline Initial & 5,3 & 5,6 & 6,0 & 7,0 \\
\hline Final & 7,4 & 6,8 & 7,7 & 8,0 \\
\hline \multicolumn{5}{|c|}{ Bread } \\
\hline Specific volume, $\mathrm{cm}^{3} / \mathrm{g}$ & 1,8 & 2,1 & 2,2 & 2,3 \\
\hline Porosity, \% & 64,0 & 66,0 & 67,0 & 67,7 \\
\hline Acidity, degrees & 6,4 & 6,8 & 6,4 & 6,8 \\
\hline Form-stability & 0,36 & 0,4 & 0,43 & 0,46 \\
\hline
\end{tabular}

The presented research results allow to widen methods of the rye-wheat bread production at mini-enterprises and restaurant economy institutions preserving freshness and smell of bakery products at storage.

\section{Conclusions}

The recipes of PCA “Optimal 1" and "Optimal 2" were elaborated on the base of experimental-statistical methods.

The production of bread on acidifiers proves the essential shortening of the technological process.

It was established, that bread samples by the accelerated technology at using PCA "Optimal 1" and "Optimal 2" have the higher value of indices of elastic and plastic deformation of bread crumb during the whole storage.

It was proved, that bound moisture losses in bread samples with the elaborated PCA are less than in samples at the existent accelerated technology.

It was established, that the addition of PCA "Optimal 1" and "Optimal 2" favors the aromatic substances preservation in both crumb and crust of studied samples comparing with the control.

Thus, the obtained results prove the expedience of using the elaborated polycomponent acidifiers "Optimal 1" and "Optimal 2" in the technology of rye-wheat bread sorts for accelerating the technological process and prolonging the storage life.

The obtained results of the researches is a base for elaborating new accelerated technologies for the production of rye-wheat sorts of bread and bakery product, which composition includes diverse grainy cultures. 


\section{References}

[1] Sokolov, A. I. (2012). Ryinok khleba i khlebobulochnyih izdeliy Ukrainyi. Produktyi i ingredientyi, 8, 34-36.

[2] Gromtsev, S. A., Gromtsev, A. S., Chervyakov, O. M. (2013). Osobennosti proizvodstva rzhano-pshenichnogo khleba v polevyh usloviyah. Nauchnyiy zhurnal NIIU ITMO, 3. Available at: https://cyberleninka.ru/article/n/osobennosti-proizvodstva-rzhano-pshenichnogo-hleba-v-polevyh-usloviyah

[3] Anderson, K. (2011). Low protein, high dockage and FM, low wheat price. Southwest Farm Press. Available at: http://www.southwestfarmpress.com/grains/low-protein-high-dockage-and-fm-lowwheat-price

[4] Kulinich, V., Sylchuk, T., Drobot, V., Tsirulnikova, V. (2016). Pat. No. 112908 UA. The complex acidulant “Optimal-1". MPK A21D 8/02. No. a201501348; declareted: 18.02.2015; published: 10.11.2016, Bul. No. 21.

[5] Kulinich, V., Sylchuk, T., Drobot, V., Tsirulnikova, V. (2016). Pat. 112367 UA. The complex acidulant “Optimal-2". No. MPK A21D 2/08, A21D 8/04. No. a201501344; declareted: 18.02.2015; published: 25.08.2016, Bul. No. 16.

[6] Pashhenko, L. P., Zharkova, I. M. (2014). Tekhnolohyia khlebopekarnogo proizvodstva. Saint Petersburg: Lan, 672.

[7] Gatapova, N. Ts., Koliuh, A. N., Orlova, N. V., Orlov, A. Yu. (2014). Osnovyi teorii i tehniki fizicheskogo modelirovaniya i eksperimenta. Tambov, 77.

[8] Lebedenko, T. E., Pshenyshniuk, H. F., Sokolova, N. Iu. (2014). Tekhnolohiia khlibopekarskoho vyrobnytstva. Odessa: Osvita Ukrainy, 392.

[9] Drobot, V. I. (Ed.) (2015). Tekhnokhimichnyi kontrol syrovyny ta khlibobulochnykh i makaronnykh vyrobiv. Kyiv: Kondor-Vydavnytstvo, 972.

[10] Reuben, B., Coultate, T. (2009). On the rise. Chemistry World, 10, 54-57.

[11] Bortnichuk, O. V., Gavrysh, A. V., Nyemirich, O. V., Docenko, V. F. (2015). Innovaciyni pidkhody v tekhnologii khlibobulochnikh vyrobiv z sukhoyu molochnoyu syrovatkoyu. Kharchova nauka i tekhnologiya, 2 (31), 97-102.

[12] Palyvoda, S. D. (2010). Udoskonalennya tekhnologiyi makaronnykh ta khlibnykh vyrobiv vykorystannyam kharchovykh dobavok strukturoutvoryuvalnoi dii. NUKHT. Kyiv, 21. 